\title{
TECNOLOGIAS DE PROTOTIPAGEM APLICADAS AO ENSINO: O PROCESSO DO DESIGN NO SUPORTE À APRENDIZAGEM
}

\section{PROTOTYPING TECHNOLOGIES APPLIED TO TEACHING: THE DESIGN PROCESS IN LEARNING SUPPORT}

\author{
Luiza Magalhães Côrtes ${ }^{1}$, graduanda \\ Lia Paletta Benatti² ${ }^{2}$ M.Sc. \\ Bárbara Arantes de Paula ${ }^{3}$, mestranda \\ (1) Universidade do Estado de Minas Gerais \\ e-mail: $\underline{\text { luhmcortes@gmail.com }}$ \\ (2) Universidade Federal de Juiz de Fora \\ e-mail:lia.paletta@gmail.com \\ (3) Universidade do Estado de Minas Gerais \\ e-mail: emailparabarbara@gmail.com
}

Palavras-chave: desenho técnico, tecnologia aplicada no ensino, prototipagem rápida

\begin{abstract}
Com o constante avanço tecnológico nas áreas de engenharia, arquitetura e design, o mercado de trabalho tornou-se ainda mais exigente com as aptidões requisitadas e, como suporte ao uso de muitas destas tecnologias, o desenho técnico é pleiteado como conhecimento estrutural. Os saberes em desenho técnico requerem constantes habilidades de visualização tridimensional e noções espaciais para lidar com o artefato projetado, porém há constantes dificuldades vivenciadas pelos alunos em sala de aula, seja pelo curto período de tempo à serem dedicados a estes estudos ou mesmo pelo distanciamento propiciado entre o maquinário industrial e as escolas de design, sem que haja aplicação efetiva do conhecimento adquirido. Baseado em pesquisas de recursos já utilizados, esta pesquisa apresenta uma proposta que visa otimizar o ensino do desenho técnico através do auxílio da tecnologia de prototipagem rápida, presente e acessível no FabLab da Escola de Design, da Universidade do Estado de Minas Gerais.
\end{abstract}

\section{Key-words: technical drawing, teaching technology, rapid prototyping}

\begin{abstract}
Among the constant technological advancement in engineering, architecture and design, the labor market has become even more demanding with the required skills and, as a support for the use of many of these technologies, the technical drawing is pleaded as structural knowledge. The knowledge in technical drawing requires constant three-dimensional visualization skills and spatial notions to deal with the projected artifact, but there are constant difficulties experienced by the students in the classroom, either for the short period of time to be dedicated to these subjects or even for the distancing caused between industrial machinery and design schools, without an effective application of the knowledge acquired. Based on researches of resources already used, this research presents a
\end{abstract}




\section{$16^{\circ}$ \\ ERGODESIGN USIHC CINAHPA}

$16^{\circ}$ Ergodesign - Congresso Internacional de Ergonomia e Usabilidade de Interfaces Humano Tecnológica: Produto, Informações Ambientes Construídos e Transporte

$16^{\circ}$ USIHC - Congresso Internacional de Ergonomia e Usabilidade de Interfaces Humano Computador

CINAHPA | 2017 - Congresso Internacional de Ambientes Hipermídia para Aprendizagem.

proposal that aims to optimize the teaching of technical drawing through the aid of rapid prototyping technology, present and accessible in the FabLab of the School of Design, State University of Minas Gerais.

\section{Introdução}

O desenho técnico é o método de representação gráfica que permite expressar a forma, a dimensão e a posição exatas dos objetos, de acordo com as necessidades dos profissionais das áreas de engenharia, arquitetura e design para a reprodução tridimensional daquilo que foi projetado.

Diferentemente de desenhos artísticos, pinturas ou croquis, onde o artista possui liberdade criativa, os desenhos técnicos são estruturados com uma organização rígida e exigência de exatidão, além do uso de normas técnicas, utilizadas para garantir melhor compreensão e interpretação dos profissionais que irão transformar os desenhos em artefatos com precisão.

De acordo com Ching (2011), o ato de desenhar não é só uma questão técnica, é também uma ação cognitiva que envolve percepção visual; avaliação e raciocínio de dimensões; e relacionamentos espaciais. Ao longo do desenvolvimento dos projetos, umas das ferramentas que permanece constantemente ao redor do designer é o desenho. À mão livre, com o auxílio de instrumentos ou digital, o desenho é a ferramenta que acompanha este profissional durante sua carreira, nas mais diversas áreas de atuação. Sketch, esboço, ilustração, desenho final, desenho conceitual, desenho técnico, desenho de apresentação, ilustração técnica, são alguns exemplos de numerosas modalidades que requisitam a habilidade do desenho e o incorporam a carreira do designer, uma das linguagens mais fluentes nas referidas áreas de atuação. A relação é tão intensa entre a área do saber e esta habilidade que, em muito idiomas, a denominação das duas é a mesma. (ISODA, 2013) Com esta afirmação, podemos dizer que o profundo entendimento dos processos de fazer representações gráficas de acordo com os parâmetros estabelecidos pela Associação Brasileira de Normas Técnicas (ABNT), normas brasileiras que padronizam o formato dos documentos para melhor organização e interpretação, torna-se extremamente necessário e exige uma metodologia de ensino que traga resultados positivos tanto aos olhos dos professores quanto dos alunos.

Atualmente no Brasil, a grande parte dos docentes ainda aplicam o método tradicional de ensino da disciplina de desenho técnico, com materiais como quadro e giz, projetor, exercícios impressos, acompanhados de equipamentos em maior escala como os esquadros, réguas e compassos para o uso do professor. Posteriormente à introdução ao desenho, as disciplinas prosseguem em aulas que se utilizam de softwares como suporte à atividade, facilitando o quesito precisão no ato de desenhar, porém é percebido uma tendência na qual há a substituição do tempo dedicado ao exercício de desenho à mão livre, em detrimento do ensino de softwares de desenho. Tal método tem trazido uma considerável dificuldade no aprendizado da disciplina, levando os profissionais a realizarem representações gráficas incorretas já no exercício da profissão enquanto no mercado de trabalho.

De acordo com estudo da Universidade Estadual Paulista - UNESP (PORVIR, 2013) sobre objetos de aprendizagem, a introdução de suportes tecnológicos no ensino das disciplinas de nível médio, como matemática e física, aprimorou em $32 \%$ o aproveitamento dos alunos. A criação de novos recursos que inovem as metodologias de ensino fortalece a propagação de novas tecnologias no país, acompanhando os estudantes que se mantém cada vez mais cercados de aparelhos eletrônicos de última geração. Partindo deste pressuposto, a fim de aprimorar a metodologia de ensino da disciplina de desenho técnico, esta pesquisa apresenta a utilização de tecnologias de prototipagem rápida e o processo do design durante o ensino destes saberes, buscando dar suporte à melhoria do processo de aprendizagem das representações gráficas.

Realização:




\section{$16^{\circ}$ \\ ERGODESIGN USIHC CINAHPA}

\section{Orientações Gerais}

O desenvolvimento tecnológico e a intensa propagação de seu uso em nosso quotidiano estimulam o constante aumento na concorrência entre as empresas por inovação, incentivando não só o surgimento de novas tecnologias produtivas como tornando o mercado de trabalho ainda mais exigente. Assim, visando aprimorar a estrutura curricular de cursos superiores ou técnicos, que desenvolvam as disciplinas de desenho técnico, projetivo ou similares como as áreas de Engenharia, Arquitetura e Design, requisita-se um aprendizado mais sólido deste saber, aprofundando questões que permeiam o raciocínio, o senso de rigor geométrico e a organização durante a execução do detalhamento.

Todavia, ao decorrer do exercício didático, é notável que muitos alunos apresentem dificuldades essenciais, principalmente com relação à interpretação das vistas ortográficas. Tais dificuldades ocorrem pela falta de uma metodologia de ensino que se alie com a tecnologia, agindo como suporte ao aprendizado destes estudantes.

A utilização de suportes de ensino que representem objetos reais e que se enquadrem no contexto de vida e aprendizado do aluno, pode reduzir esta dificuldade e, para expandir esse campo, as tecnologias de prototipagem se mostram ideais. Processos rápidos, acessíveis, de baixo custo e que estão presentes nas universidades, podem se tornar interessantes aliados dos professores.

Com o intuito de promover um método que apresente expressiva melhoria na metodologia de ensino de desenho técnico através de um processo de design, acessível e de baixo custo, como o uso da tecnologia de prototipagem, esta pesquisa buscou mapear os recursos didáticos já utilizados nas disciplinas de desenhos técnicos em cursos técnico/profissionalizantes e cursos superiores; desenvolver propostas de novos recursos que visem otimizar o ensino e o aprendizado a partir das tecnologia de prototipagem rápida; e a avaliação o material e verificação de efetividade da proposta por professores da disciplina. $16^{\circ}$ Ergodesign - Congresso Internacional de Ergonomia e Usabilidade de Interfaces Humano Tecnológica: Produto, Informações Ambientes Construídos e Transporte

$16^{\circ}$ USIHC - Congresso Internacional de Ergonomia e Usabilidade de Interfaces Humano Computador

CINAHPA | 2017 - Congresso Internacional de Ambientes Hipermídia para Aprendizagem.

\subsection{Desenho técnico}

A viabilização de boas ideias e o bom resultado final de um projeto que envolve conhecimentos específicos de engenharia ou arquitetura dependem de cálculos, estudos econômicos, análise de riscos e pesquisa de propriedades de materiais a serem usados que são resumidos e apresentados de maneira sistematizada em desenhos, através de gráficos ou diagramas. Projetar um produto está relacionado à expressão gráfica desde o início da criação até seu protótipo. O desenho técnico é uma categoria de registro que busca facilitar a apresentação de resultados em soluções gráficas e sua padronização é o modo de estandardizar os conceitos ali expressos. Apesar do amplo desenvolvimento tecnológico no setor e o intenso uso de softwares para a execução de representações gráficas, o ensino do desenho técnico ainda se faz indispensável na formação de bons profissionais, dado que o aprendizado de tal a disciplina incentiva o desenvolvimento de processos de abstração, melhor entendimento de perspectivas, raciocínio, organização e execução de padrão da linguagem gráfica a ser apresentada à terceiros, uma vez que o processo produtivo dos artefatos desenvolvidos por designers comumente é executado em outra instância.

As representações técnicas de objetos tridimensionais em planos bidimensionais existem há mais de dois séculos e as formas de representação evoluíram muito desde a sua criação. De acordo com Hoelscher, Springer e Dobrovolny (1978), um dos exemplos mais antigos de documentos que apresenta planta e elevação que se tem conservado está no álbum de desenhos na Livraria do Vaticano desenhado por Giuliano de Sangalo no ano de 1490.

Porém, somente em 1795 que se registra o início da história do desenho técnico, quando o matemático francês Gaspard Monge (1746-1818) desenvolveu um método construtivo conhecido por geometria descritiva. $\mathrm{O}$ método de registro elaborado por Monge fazia com que os elementos do plano e do espaço se correspondessem um com o outro através de projeções ortogonais, propiciando que este sistema se transformasse na

Realização:




\section{$16^{\circ}$ \\ ERGODESIGN USIHC CINAHPA}

base da linguagem dos desenhos técnicos e propiciando a primeira linguagem que representasse bidimensionalmente elementos puramente tridimensionais..

A padronização dos procedimentos de representação técnica é feita por meio de normas respeitadas internacionalmente. Essa normatização é resultante do esforço cooperativo dos interessados em estabelecer códigos técnicos que regulem relações entre produtores e consumidores, projetistas, construtores e clientes.

No Brasil, as normas são editadas e aprovadas pela Associação Brasileira de Normas Técnicas (ABNT), instituição fundada em 1940. Para favorecer o desenvolvimento da padronização internacional e facilitar o intercâmbio de produtos e serviços entre as nações, os órgãos responsáveis pela normalização em cada país, se reuniram em Londres e estabeleceram, em 1947, a Organização Internacional de Normalização (ISO ou International Organization for Standardization). As normas técnicas que regulam o desenho técnico são normas editadas pela ABNT, registradas pelo INMETRO (Instituto Nacional de Metrologia, Normalização e Qualidade Industrial) como normas brasileiras (NBR) e estão em consonância com as normas internacionais aprovadas pela ISO.

Para alcançar as qualificações essenciais a um bom projetista, antes de aprender a manipulação de programas computadorizados que facilitam a projeção de representações gráficas padronizadas, há a necessidade de dominar a execução de desenhos técnicos através do método mais tradicional: à mão livre.

\subsection{Recursos didáticos já utilizados}

A constante e insaciável evolução dos processos tecnológicos permeia hoje todas as instâncias da vida quotidiana, para tanto, o modo de projetar através de desenhos como linguagem de representação sistematizada, que iniciaram a partir do século XV e XVI (MARTINEZ, 1990, p. 13) também não pararam de evoluir desde então.

Disseminado o conhecimento relativo à Geometria $16^{\circ}$ Ergodesign - Congresso Internacional de Ergonomia e Usabilidade de Interfaces Humano Tecnológica: Produto, Informações Ambientes Construídos e Transporte

$16^{\circ}$ USIHC - Congresso Internacional de Ergonomia e Usabilidade de Interfaces Humano Computador

CINAHPA | 2017 - Congresso Internacional de Ambientes Hipermídia para Aprendizagem.

Descritiva de Gaspar Monge e do estabelecimento das normas técnicas, a evolução da tecnologia construtivas permitiu que a criação e desenvolvimento de projetos fossem feitos com o auxílio de sistemas computadorizados e técnicas prototipagem rápida, ampliando seu acesso e acelerando a produção de tais. No Brasil, a aplicação dessas técnicas ainda é prematura e isso se deve a dois grandes fatores: econômico e social. O econômico está relacionado aos altos custos dos equipamentos e insumos necessários, em sua maioria importados dos Estados Unidos, Europa e China, embora recentemente algumas empresas nacionais tenham começado a investir no desenvolvimento e produção de maquinário para fabricação digital. Existe ainda uma grande limitação social ao emprego das técnicas de fabricação digital na área de arquitetura e construção no Brasil, pela escassez de mão de obra especializada no setor. (PUPO, 2008)

Com todas essas dificuldades, podemos dizer que o Brasil caminha, porém a passos lentos, para a plena utilização de ferramentas de prototipagem rápida dedicadas ao ensino, mas estes casos são mais comumente vistos em cursos de medicina ou engenharia, escolas que normalmente contam com maior investimento acadêmico. Equipamentos inacessíveis e a falta de estrutura que possibilite acesso à tecnologias necessárias nas escolas são fatores que obrigam a continuação do ensino tradicional e engessado de desenho técnico nas escolas brasileiras, ocasionando a constante falta de qualificação profissional e alimentando o ciclicamente a demanda de profissionais qualificados para evolução do setor no país.

Para melhor pesquisar os recursos didáticos já utilizados em salas de aula de desenho técnico de algumas escolas e universidades brasileiras, incluindo a Escola de Design da UEMG, foram utilizados artigos e questionários, além de intensa investigação à pesquisas similares, além da realização de observações dos espaços e laboratórios da supracitada Escola de Design.

\subsection{Prototipagem rápida}

Tecnologia surgida na década de 1980 através da
Realização:

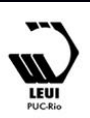




\section{$16^{\circ}$ \\ ERGODESIGN USIHC CINAHPA}

introdução da estereolitografia, processo em que camadas de um polímero líquido sensível à luz ultravioleta é solidificada usando tecnologia a laser, a prototipagem rápida ou manufatura aditiva é um conjunto de tecnologias construtivas de objetos físicos a partir de modelagens desenvolvidas em sistemas de projeto auxiliado por computador, o CAD (Computer Aided Design).

(VOLPATO, 2006)

\subsection{A Escola de Design da Universidade do Estado de Minas Gerais}

Pioneira, considerada a primeira escola de design em Minas Gerais e a segunda do país, a Escola de Design da Universidade do Estado de Minas Gerais foi estabelecida no ano de 1955.

Atualmente, disponibiliza de diversos laboratórios de design, sendo dois desses dedicados ao ensino do desenho técnico e desenvolvimento de projetos com o auxílio de programas computadorizados e sistemas de prototipagem tridimensional: os laboratórios de informática e o Fab Lab do Centro Design Empresa. Além dos laboratórios, a Escola de Design dispõe de salas de aulas dedicadas ao ensino de desenho técnico. No laboratório de informática são realizadas as disciplinas de representação técnica e representação tridimensional, que ensinam o desenvolvimento de projetos através de programas como AutoCAD, SolidWorks, SketchUp, dentre outros, sendo provido de 40 computadores, um projetor e quadro branco para o auxílio das aulas. A disponibilidade das mesas, computadores e assentos são ergonomicamente corretos, tornando o laboratório satisfatório para a realização de suas atividades: 384 horas totais de representação técnica e tridimensional nos cursos de Design de Produto e Gráfico, 192 dessas horas para desenho técnico e a outra metade voltada ao ensino dos respectivos programas computadorizados $\mathrm{CAD} ; 286$ horas totais de representação técnica e tridimensional no curso de Artes Visuais, sendo 128 de desenho técnico e o restante de programas computadorizados; e 320 horas totais de representação técnica no curso de Design de Ambientes, de acordo com as cargas horárias exigidas na matriz curricular da UEMG. $16^{\circ}$ Ergodesign - Congresso Internacional de Ergonomia e Usabilidade de Interfaces Humano Tecnológica: Produto, Informações Ambientes Construídos e Transporte

$16^{\circ}$ USIHC - Congresso Internacional de Ergonomia e Usabilidade de Interfaces Humano Computador

CINAHPA | 2017 - Congresso Internacional de Ambientes Hipermídia para Aprendizagem.
O Fab Lab é um espaço que disponibiliza de equipamentos modernos e de alta qualidade, dedicados ao auxílio no desenvolvimento de projetos. Neste espaço constam 6 computadores e 5 máquinas que possuem sistemas de prototipagem rápida. Coordenado por professores da Escola de Design e auxiliado por diversos alunos monitores da própria universidade, o Fab Lab se mantém aberto aos estudantes, professores da Escola de Design e à comunidade em geral, possibilitando tornar seus projetos em protótipos em formato tridimensional. Sendo uma ferramenta muito importante que auxilia no avanço dos projetos, a prototipagem rápida pode ser também utilizada como um processo de design que dê suporte à aprendizagem de vistas espaciais, e como este projeto tem o intuito de focar nessa tecnologia para aplicar no ensino de Desenho Técnico, foram resumidos os equipamentos existentes no Fab Lab da Escola de Design:

a) 3D Cloner DH (figura 1): impressora com estrutura de monobloco produzida pela Indústria Schumacher Ldta. com o objetivo de criar protótipos em 3D com baixo custo de produção, alta qualidade e rapidez através da tecnologia de FDM (fusão e deposição de material). $\mathrm{O}$ equipamento trabalha através da adição do material plástico em camadas, onde carretel do material é desenrolado e passado ao bico de extrusão, que faz o controle da fusão e da deposição de material. A ponta do bico aquece o material a ser depositado, em uma área máxima de 320x210x400mm (comprimento $\mathrm{x}$ largura $\mathrm{x}$ altura), movendo seu eixo em sentidos horizontal e vertical (XY), controlado por um software de manufatura assistida por computador (CAM), a fim de formar camadas sucessivas de deposição de material.

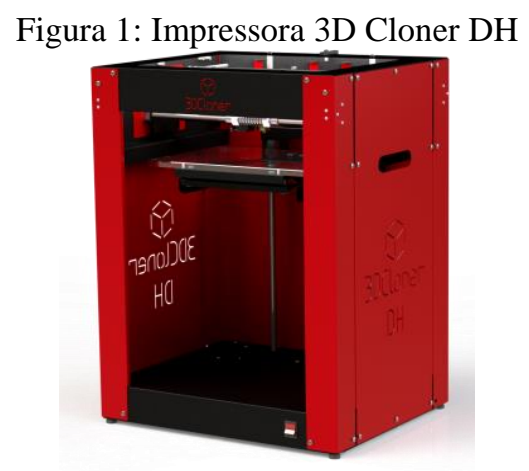




\section{$16^{\circ}$ \\ ERGODESIGN USIHC CINAHPA}

$16^{\circ}$ Ergodesign - Congresso Internacional de Ergonomia e Usabilidade de Interfaces Humano Tecnológica: Produto, Informações Ambientes Construídos e Transporte

$16^{\circ}$ USIHC - Congresso Internacional de Ergonomia e Usabilidade de Interfaces Humano Computador

CINAHPA | 2017 - Congresso Internacional de Ambientes Hipermídia para Aprendizagem.
Fonte: Site da 3D Cloner DH

b) Corte a laser L-1060 (figura 2): corta e/ou grava em alta velocidade materiais não-metálicos através do laser $\mathrm{CO}^{2}$ emitido da ponta do bico, em área útil 1000x600mm e com baixo consumo de energia.

Este equipamento possui monitoramento automático de temperatura e fluxo de água do tubo laser e trabalha em uma grande variedade de materiais, os mais comumente utilizados no Fab Lab são o MDF (medium density fiberboard) e papel-paraná.

Figura 2: Máquina de Corte a Laser L-1060

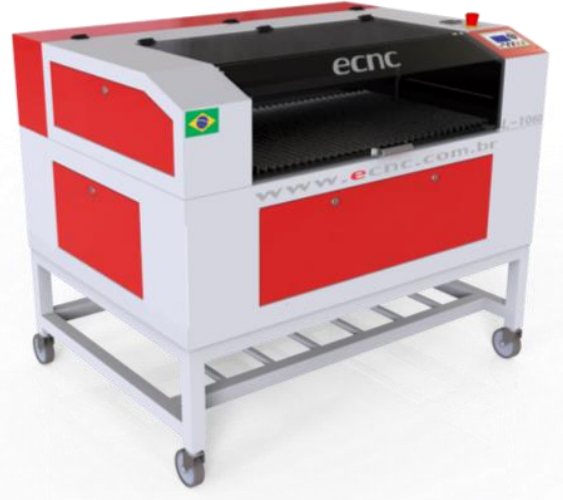

Fonte: Site da ECNC - Máquinas de corte a laser

c) Máquina modeladora 3D MDX-40A (figura 3): fabricada pela Roland DG Corporation, esta modeladora utiliza a tecnologia SRP (Prototipagem Rápida por Subtração) na formação de peças e protótipos em 3D feitos a partir de variados tipos de materiais como ABS, nylon, acrílico, cera de joalheria, resinas como madeira química e ceras de modelar, etc.

Figura 3: Máquina Modeladora 3D MDX-40A

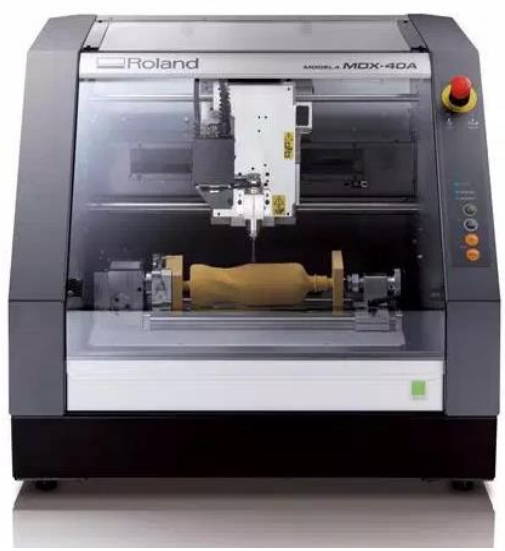

Fonte: Site da Roland DG

\section{Desenvolvimento}

Visando desenvolver objetos didáticos que suportem o ensino e aprendizagem de desenho técnico, através da tecnologia de prototipagem existente no FabLab da Escola de Design e verificar os obstáculos enfrentados por alunos na hora de assimilar a disciplina, foram realizadas entrevistas através de questionários com professores do assunto e com estudantes de todos os cursos da Escola de Design.

Filtrando as informações obtidas, foi possível perceber que os cinco docentes de desenho técnico que foram entrevistados e mais $71 \%$ dos 69 estudantes que responderam ao questionário concordam que a disciplina é indispensável para o aprendizado e o desenvolvimento dos alunos ao elaborarem projetos de resultado físico, além de melhorar visão espacial, habilidade contiguamente requerida na carreira de designer.

Muitos alunos iniciaram a graduação na Escola de Design sem conhecimentos prévios acerca de geometria e/ou perspectiva, dificultando o aprendizado tardio da disciplina de representação técnica, que exige plena percepção visual do espaço e, o uso dos programas de desenhos auxiliados por computador, sem que haja o exercício do aprendizado à mão, pode comprometer os resultados do processo de aprendizagem, visto que a ferramenta CAD é apenas um artifício utilizado para otimizar o fazer em projetos. A percepção visual do espaço é estruturalmente afetada quando não há conhecimento elementar sobre o desenho técnico.

O gráfico 1 a seguir apresenta as respostas dos 69 alunos em relação à pergunta em destaque, através do qual ponderam adequadamente as necessidades de aprimoramento do ensino do desenho técnico.
Realização:

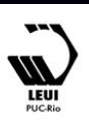




\section{$16^{\circ}$ \\ ERGODESIGN USIHC CINAHPA}

$16^{\circ}$ Ergodesign - Congresso Internacional de Ergonomia e Usabilidade de Interfaces Humano Tecnológica: Produto, Informações Ambientes Construídos e Transporte

$16^{\circ}$ USIHC - Congresso Internacional de Ergonomia e Usabilidade de Interfaces Humano Computador

CINAHPA | 2017 - Congresso Internacional de Ambientes Hipermídia para Aprendizagem.
Gráfico 1: "Qual tópico da disciplina você teve mais dificuldade em aprender?"

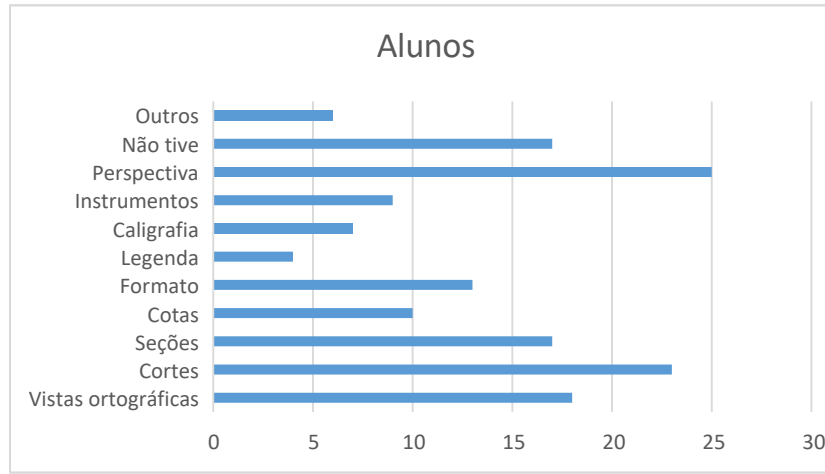

Fonte: autora (2016).

É percebido que as maiores dificuldades dos alunos são relacionados à perspectivas $(36,2 \%)$, aos cortes $(33,3 \%)$, vistas ortográficas $(26,1 \%)$ e seções $(24,6 \%)$.

No gráfico 2, são apresentada as respostas dos alunos referentes ao questionamento que indaga sugestões ao aprimoramento da disciplina. Podemos perceber que dois dos três maiores interesses dos alunos no aprimoramento do aprendizado do desenho técnico são relacionados ao focos da pesquisa e se relacionam à maior presença da tecnologia em salas de aulas $(56,5 \%)$ e mais protótipos como exemplos de exercícios $(40,6 \%)$.

Gráfico 2: “Qual a sua sugestão para melhorar a disciplina?"

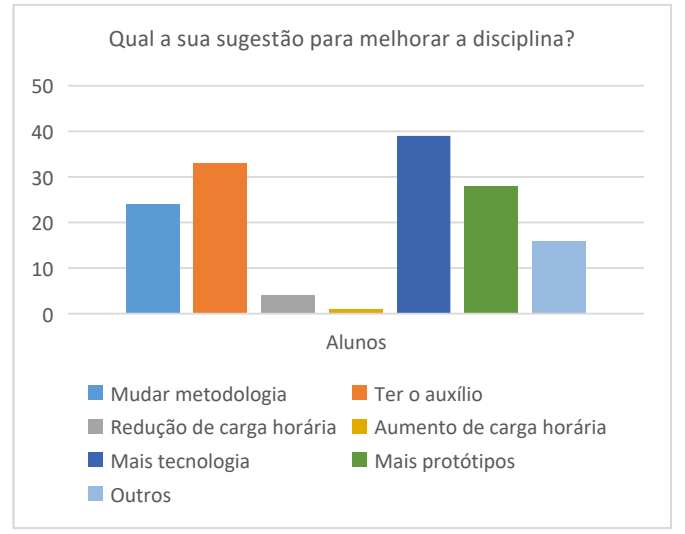

Fonte: a autora (2016).

Com o intuito de melhorar o aprendizado das representações técnicas, foi elaborada a proposta de utilizar a tecnologia de prototipagem rápida, com o propósito de facilitar o entendimento nas questões que concernem a perspectiva visual do espaço e dos desenhos técnicos.

Em prosseguimento a análise das informações obtidas através das entrevistas com os professores, alunos e ex-alunos, foi criada uma proposta que visa utilizar um processo de design como método, a fim de aprimorar o aprendizado do desenho técnico e auxiliar, tanto o professor quanto alunos a atingirem as exigências do mercado em um menor espaço de tempo.

O acervo tecnológico disponibilizado pelo FabLab do Centro Design Empresa é plenamente capaz de de proporcionar uma sólida aliança entre a tecnologia e o aprendizado do desenho técnico, uma vez que estas tecnologias suportam o desenvolvimento de protótipos que ofereçam melhores demonstrações de assuntos como perspectivas, vistas ortográficas e cortes. Para tanto, foram elaborados e modelados protótipos avaliados por um docente do Instituto Federal, como proposta de se trabalhar em intercâmbio com outra instituição, avaliando a possibilidade de replicação e ampla absorção dos modelos propostos.

As figuras 4, 5 e 6 mostram os protótipos criados através de três tecnologias diferentes oferecidas pelo FabLab.

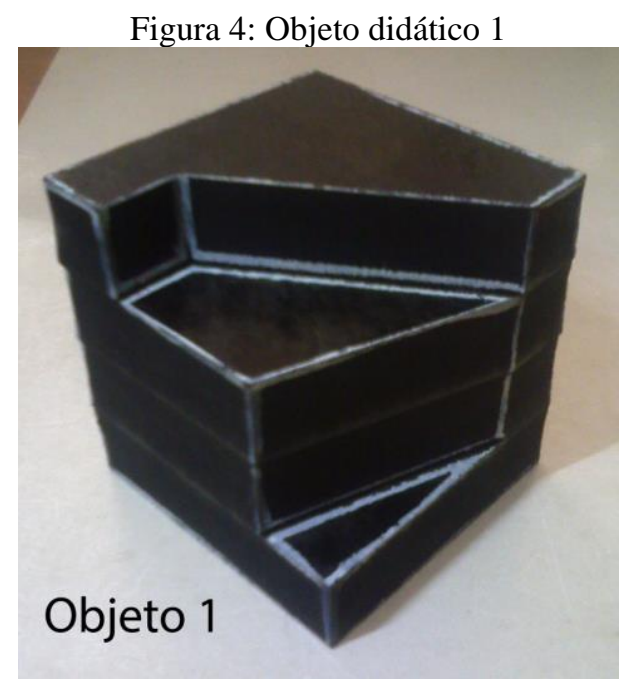

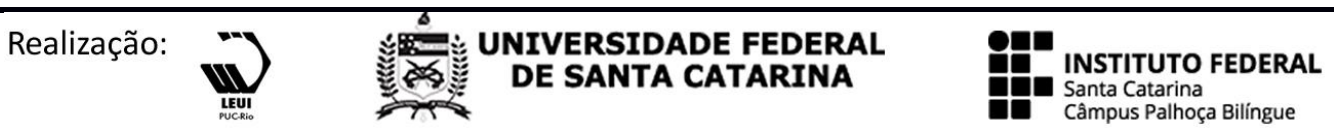




\section{$16^{\circ}$ \\ ERGODESIGN USIHC CINAHPA}
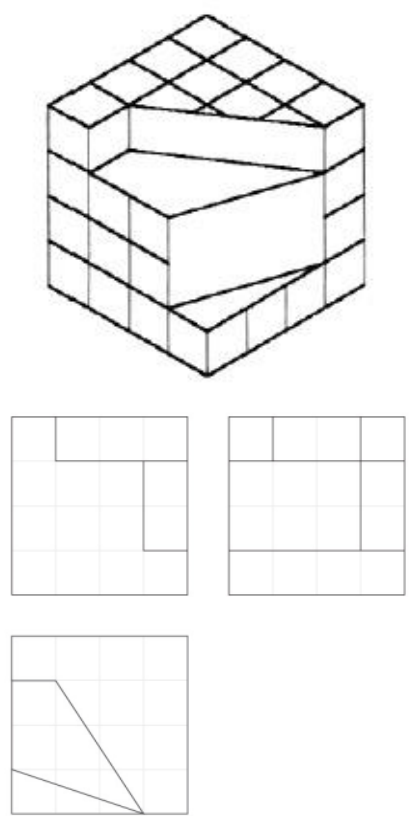

Fonte: da autora.

O objeto 1 é um protótipo criado a partir da máquina de corte a laser em MDF, posteriormente aglutinando as partes, uma sobre a outra. Este protótipo tem o objetivo de aprimorar as vistas ortográficas e perspectivas dos estudantes, deve ser apresentado junto ao exercício impresso com o objetivo de auxiliar visualização das vistas ortogonais.

Figura 5: Objeto didático 2

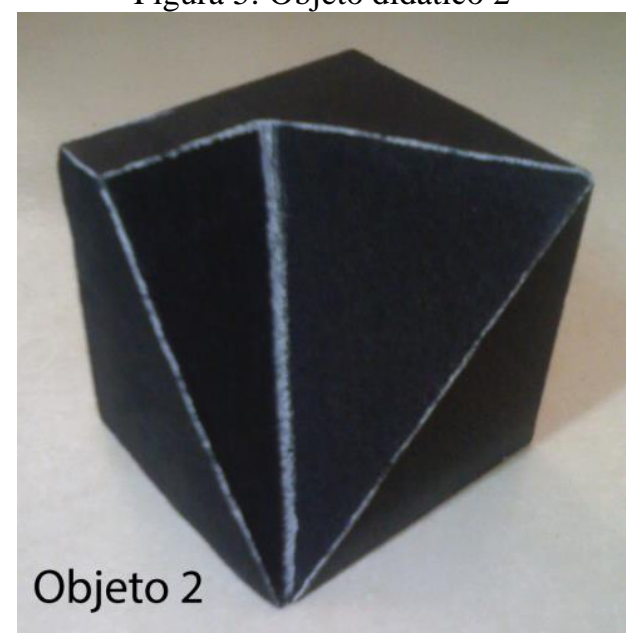

$16^{\circ}$ Ergodesign - Congresso Internacional de Ergonomia e Usabilidade de Interfaces Humano Tecnológica: Produto, Informações Ambientes Construídos e Transporte

$16^{\circ}$ USIHC - Congresso Internacional de Ergonomia e Usabilidade de Interfaces Humano Computador

CINAHPA | 2017 - Congresso Internacional de Ambientes Hipermídia para Aprendizagem.
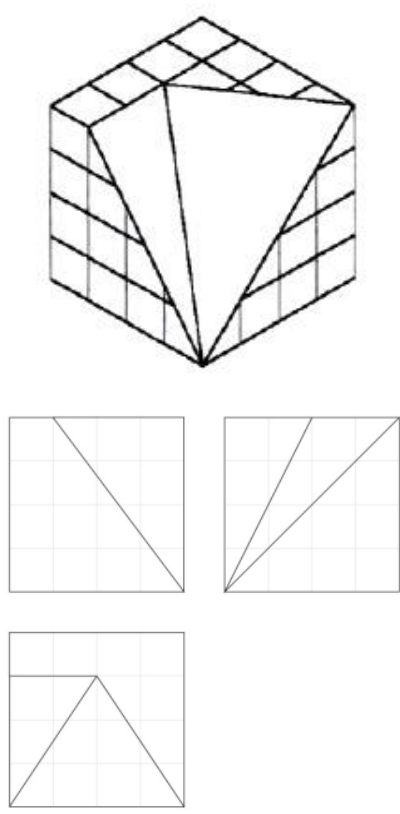

Fonte: da autora.

O objeto 2 foi produzido com a máquina modeladora através de subtração, em que um pedaço de poliuretano foi cortado de acordo com o controle do software. Este protótipo tem o objetivo de aprimorar as vistas ortográficas e perspectivas dos estudantes, assim como o objeto 01 (figura 4), porém seu processo produtivo permite a construção em ângulo.

Figura 6: Objeto didático 3

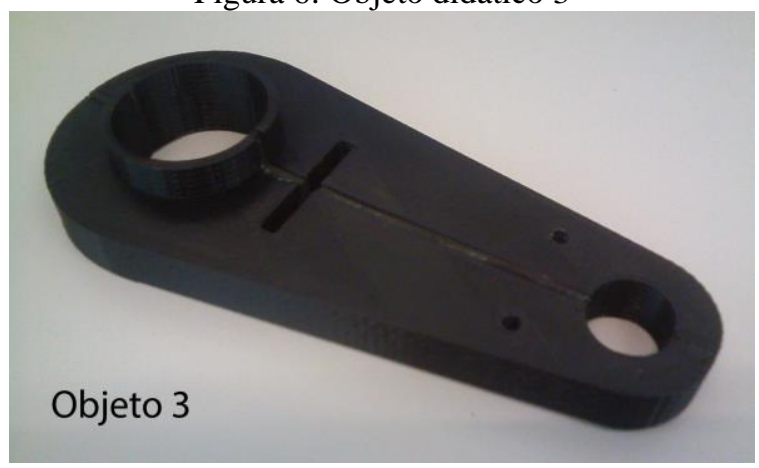


$16^{\circ}$ USIHC - Congresso Internacional de Ergonomia e Usabilidade de Interfaces Humano Computador

CINAHPA | 2017 - Congresso Internacional de Ambientes Hipermídia para Aprendizagem.
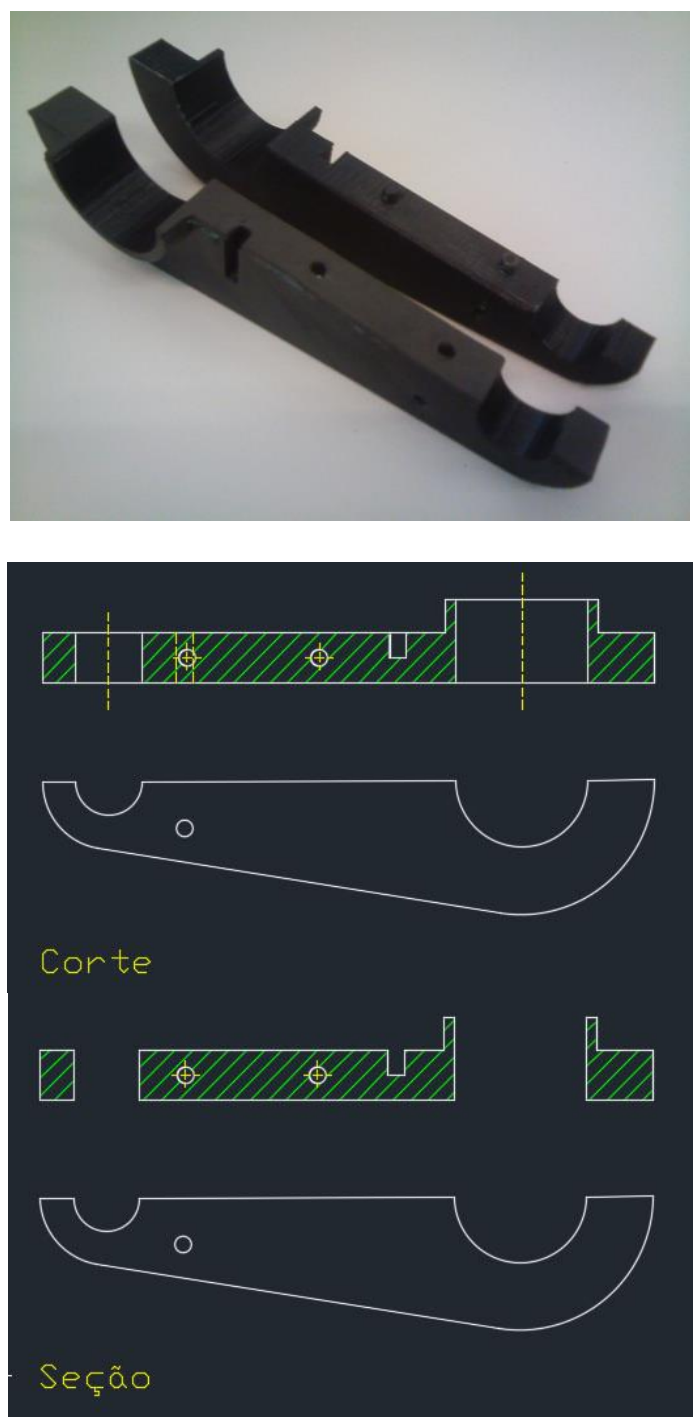

Fonte: da autora (2016).

O objeto 03, por sua vez foi produzido por impressão 3D através de adição de camadas, dividido em duas partes que se encaixam para o entendimento do uso de cortes em desenho técnico. Ao meio da peça foi adicionado material macio (EVA) para ser usado como um carimbo de forma que este meio represente a seção do protótipo como um todo, com o objetivo de auxiliar tanto os alunos quanto os professores, além de aprimorar as vistas ortográficas e as perspectivas dos alunos.

\section{Resultados}

Como forma de verificar o resultado do trabalho desenvolvido na Escola de Design, foi realizado também um questionário com o professor Artur Caron Mottin, phD., do Instituto Federal de Congonhas, com o objetivo de avaliar a replicação dos protótipos em outras Instituições de Ensino. Analisando as informações obtidas após as entrevistas, foi percebido que os três objetos didáticos teriam uma aplicação viável para o professor no ensino do desenho técnico, por serem de fácil apresentação e manuseio, além de reafirmar a dificuldade de alunos em fazer a transposição da peça tridimensional para o desenho bidimensional. Esses objetos melhoram a compreensão dos conceitos básicos da disciplina, diminuindo os obstáculos enfrentados pelos estudantes em relação às perspectivas, cortes, vistas ortográficas e seções das peças.

Como o aprendizado do desenho técnico é indispensável aos estudantes que desejam ter uma carreira como engenheiro, arquiteto e designer, por exemplo, e muitos alunos ingressam às universidades desprovidos do conhecimento básico da disciplina. Esta proposta poderá resultar em maior profundidade e amplitude nos estudos deste assunto, em um curto espaço de tempo, além dos baixos custos, tornando real, vantajosa e viável a possibilidade de utilização da tecnologia de prototipagem rápida como auxílio no ensino do desenho técnico.

Posteriormente à aplicação destes três objetos nas salas de aulas de desenho técnico e a observação dos efeitos do uso destes protótipos tanto positivos quanto negativos, outra solução que passível de realização é apresentar os protótipos desenvolvidos também com realidade aumentada, a ser acessada com códigos bidimensionais que possibilitam projetar objetos virtuais em uma filmagem do mundo real, proporcionando informações mais detalhadas e precisas para melhor compreensão do objeto.

\subsection{Considerações finais}

Ainda hoje, muitos estudantes brasileiros ingressam em faculdades de cursos projetuais sem terem o conhecimento básico do desenho técnico, disciplina que um dia já fez parte da estrutura curricular do ensino médio (TRINDADE, 2002), o 


\section{$16^{\circ}$ \\ ERGODESIGN USIHC CINAHPA}

que ocasiona o aprendizado tardio do saber, pouco aprofundado e em curto prazo. Tais obstáculos trazem dificuldades aos futuros profissionais em alcançar as grandes exigências do mercado de trabalho.

O avanço da tecnologia fez com que as concorrências entre as empresas de várias áreas se tornassem maiores e mais fortes, e com isso, o mercado de trabalho se tornou ainda mais rígido na busca de profissionais que possuem conhecimentos exigidos nas áreas de trabalho como projetista, mas como resolver o problema com o aprendizado tardio e em curto prazo de tempo?

A necessidade das empresas e dos profissionais em se destacarem perante as concorrências tornou-se difícil, mas ainda há a alternativa de aliar a tecnologia de prototipagem rápida com o ensino do desenho técnico, objetivo desta pesquisa.

Com base nas pesquisas realizadas através dos recursos já utilizados para a melhoria do ensino do desenho técnico e com os resultados obtidos após a averiguação dos efeitos que os novos protótipos propostos, feitos a partir da tecnologia de prototipagem rápida, podemos constatar que o acesso a estes processos pode resultar em maior interesse pela tecnologia e pela própria disciplina de desenho técnico, facilitando o aprendizado em curto prazo de tempo, possibilitando maiores noções espaciais e melhores raciocínios.

Tais protótipos propostos são capazes de diminuir os obstáculos enfrentados pelos estudantes em relação às perspectivas, cortes, vistas ortográficas e seções das peças por serem feitos pensando nas dificuldades no aprendizado do desenho técnico, tornando a proposta viável e acertada ao criar um processo de design que alia as tecnologias de prototipagem acessíveis ao ensino de desenho técnico.

\section{BIBLIOGRAFIA}

ABNT Catálogo. Normas do Desenho Técnico. Disponível em:

<http://abntcatalogo.com.br/normagrid.aspx>

Acesso em 11 de dezembro de 2016. $16^{\circ}$ Ergodesign - Congresso Internacional de Ergonomia e Usabilidade de Interfaces Humano Tecnológica: Produto, Informações Ambientes Construídos e Transporte

$16^{\circ}$ USIHC - Congresso Internacional de Ergonomia e Usabilidade de Interfaces Humano Computador

CINAHPA | 2017 - Congresso Internacional de Ambientes Hipermídia para Aprendizagem.
BERGAMASCHI, Marcelo Pereira. Um estudo da utilização de realidade aumentada associada a um sistema de apoio ao ensino de desenho técnico para o curso de engenharia. São Paulo; SP: [s.n], 2013.

Blog Provir. Estudo relaciona tecnologia e desempenho escolar. Disponível em:

$<$ http://porvir.org/estudo-relaciona-tecnologia-aodesempenho-escolar/>. Acesso em 07 de dezembro de 2016.

\section{CATTANI, Airton. Arquitetura e Representação}

Gráfica: considerações históricas e aspectos práticos. UFRGS, Arqtexto. n.9 (2006), p. 110-123.

\section{CHING, F. D. K. Representação gráfica em arquitetura. Porto Alegre: Bookman, 2011.}

Desenho Técnico. Padronização e Normas. Disponível em: <http://desenhotecnico.info/padronizacao-e-normas.html > Acesso em 11 de dezembro de 2016.

ECNC Máquinas de Corte a Laser. L-1060. Disponível em: <http://www.ecnc.com.br/l-1060ecnc.html> Acesso em: 09 de dezembro de 2016.

Engraver \& XLexno. Roland MDX 40A. Disponível em: <http://engraver.com.br/maquinasroland/roland-mdx-40a/> Acesso em: 09 de dezembro de 2016 .

Escola de Design/UEMG. Cursos de Graduação: Artes Visuais - Licenciatura. Disponível em: $<$ http://www.ed.uemg.br/cursos/graduacao/artesvisuais-licenciatura $>$ Acesso em 11 de dezembro de 2016.

Escola de Design/UEMG. Cursos de Graduação: Design de Ambientes. Disponível em: <http://www.ed.uemg.br/cursos/graduacao/designambientes> Acesso em 11 de dezembro de 2016.

Escola de Design/UEMG. Cursos de Graduação: Design de Produto. Disponível em:

<http://www.ed.uemg.br/cursos/graduacao/designproduto> Acesso em 11 de dezembro de 2016.

Escola de Design/UEMG. Cursos de Graduação: 


\section{$16^{\circ}$ \\ ERGODESIGN USIHC CINAHPA}

$16^{\circ}$ Ergodesign - Congresso Internacional de Ergonomia e Usabilidade de Interfaces Humano Tecnológica: Produto, Informações Ambientes Construídos e Transporte

$16^{\circ}$ USIHC - Congresso Internacional de Ergonomia e Usabilidade de Interfaces Humano Computador

CINAHPA | 2017 - Congresso Internacional de Ambientes Hipermídia para Aprendizagem.
Design Gráfico. Disponível em:

<http://www.ed.uemg.br/cursos/graduacao/designgrafico> Acesso em 11 de dezembro de 2016.

Escola de Design/UEMG. História. Disponível em: <http://www.ed.uemg.br/sobre-ed/historia> Acesso em 11 de dezembro de 2016.

Factory of Factories. RP - Prototipagem rápida. Disponível em:

<http://www.factoryoffactories.com/fof_br/rapidpr otot_br.htm> Acessado em: 10 de dezembro de 2016.

HOELSCHER, R. P.; SPRINGER, C. H.; DOBROVOLNY, J. S. Expressão Gráfica e Desenho Técnico. Trad. Rodrigues, R. S.; Rio de Janeiro. Livros Técnicos e Científicos, 523 p., 1978.

Impressão Fácil. Impressora 3D Cloner DH. Disponível em:

<http://www.impressao3dfacil.com.br/loja/produto /impressora-3d-3dcloner-dh/> Acesso em: 09 de dezembro de 2016.

ISODA, G. T. de Tani e. Sobre desenho: estudo teórico-visual. Dissertação (Mestrado) Universidade de São Paulo, 2013.

MARQUES, Janaína Carneiro. O Ensino do Desenho Técnico e suas relações com a História da Matemática, da Arquitetura e a Computação Gráfica. Instituto Federal do Espírito Santo, 2015.

MARTÍNEZ, Alfonso. Ensayo sobre el proyecto. Buenos Aires: Editorial CP67, 1990.

MATUICHUK, Miraldo, SILVA, Maclovia Corrêa da Silva e NASCIMENTO, Silvania Sousa do. A Disciplina de Desenho na formação profissional técnica e tecnológica: dos ofícios às engenharias. Curitiba: Universidade Tecnológica Federal do Paraná, 2011.

MELLO, Carlos Henrique Pereira; SILVA, Carlos Eduardo Sanches da; COSTA, Sebastião Carlos da Costa. Comparação de três diferentes tecnologias de prototipagem rápida em relação a critérios de custo e tempo. XXVI ENEGEP.
Fortaleza: 2006.

OLIVEIRA, Mariel Lima de. Ensino da Geometría Projetiva nos Cursos de Arquitetura e Urbanismo, em tempos de CAD/BIM. São Paulo: SIGraDi, 2009

PELISSON, Maria das Graças Contin Garcia e ESTORILIO, Carla Cristina Amódio. Estudo comparativo das estratégias de ensino utilizadas em Desenho Técnico mecânico. Universidade de Passo Fundo, 2006.

PIRES, Roberto Wanner. Proposta para diretrizes para o projeto de uma sala de aula adequada ao ensino de desenho técnico informatizado. Porto Alegre: Universidade federal do Rio Grande do Sul, 2011.

PRADELLA, Marcelo Pinto e FOLLE, Luis Fernando. Análise de mercado sobre tecnologias de prototipagem rápida por adição de material. Gramado: 11 P\&D Design, 2014.

PUPO, Regiane Trevisan. Ensino da prototipagem rápida e fabricação digital para arquitetura e construção no Brasil: definições e estado da arte. Campinas: UNICAMP, 2008.

RIBEIRO, Antônio Clélio. PERES, Mauro Pedro. IZIDORO, Nacir. Leitura e Interpretação de Desenho Técnico. Capítulo 1: Introdução ao Desenho Técnico.

TRINDADE, Bernardete. Ambiente híbrido para a aprendizagem dos fundamentos de desenho técnico para as engenharias. 2002. 188f. Tese (Doutorado em Engenharia de Produção) Programa de Pós-Graduação em Engenharia de Produção, UFSC, Florianópolis.

TAKAGAKI, Luiz Koiti. Capítulo 3: Tecnologia de Impressão 3D. São Paulo: Revista Inovação Tecnológica, v.2, n.2, p.28-40, jul./dez.2012.

VOLPATO, Neri. Prototipagem Rápida (Tecnologias e aplicações). 1. Ed. São Paulo: Blucher, 2006.
Realização:

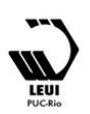

